\title{
The relationship between career maximization and employee engagement
}

\author{
Abdulaziz Alabood ${ }^{\mathrm{a}^{*}}$ and Sulphey Manakkattil ${ }^{\mathrm{b}}$
}

${ }^{a}$ Lecturer, College of Business Administration, Prince Sattam bin Abdulaziz University, Saudi Arabia

${ }^{b}$ Professor, College of Business Administration, Prince Sattam bin Abdulaziz University, Saudi Arabia

\section{H R O N I C L E}

\section{Article history:}

Received: February 16, 2020

Received in revised format:

March 222020

Accepted: March 22, 2020

Available online:

March 28, 2020

Keywords:

Career

Career maximization

Maximization

Employee engagement

\section{A B S T R A C T}

Career maximizing is the extent to which a person desires to make career decisions in pursuit of maximizing goals. It is now receiving widespread academic and research interest from various quarters. Since a career is a process wherein individuals narrow down their life choices, to create and find their self, it is of paramount importance. Employee engagement is an affective cognitive state at workplace, which is persistent and pervasive in nature. It is capable of enhancing employee empowerment, and reducing workplace deviance and turnover intentions. The study identified the relationship between career maximization and employee engagement. It was found that the two variables were having significant positive relationship. No significant difference was found in the gender wise analysis of the two constructs. The study has brought out significant addition to management literature as no earlier studies have been done to identify the relationships.

(C) 2020 by the authors; licensee Growing Science, Canada

\section{Introduction}

Maximization is the quest for individuals to discover the best available option. It is the tendency. Maximisers have the general tendency to identify the optimal alternative, and select the best option that has the highest expected utility (Simon, 1978). They rely on external information tend to make upward social comparisons, creating regretful and "counterfactual thinking about what might have been" (Iyengar, et al., 2006). This could, in turn, lead to further questioning the choices made by them. Parker et al. (2007) found though maximizing could result in better outcomes and there could be less satisfaction with the outcomes. The present study focuses more on career maximization than general maximization. Studies about career and career decisions date back to many decades (Hughes, 1937; Goffman, 1968). It has received research and academic interest from various quarters. There are volumes of empirical works about career and related topics (Dahling \& Thompson, 2012; Iyengar, et al., 2006, Voss et al., 2018). Career decisions requires a complex and lengthy process that normally involves detailed examination, evaluation, as well as comparing of the available options so that the best available decision can be taken (Voss et al., 2019). Since career decisions involve long-term implications, it requires to be taken with care, prudence and caution. The need for care and caution often induce individuals to maximize their career decisions. Maximizing means carefully weighing all available options and choosing the best and the optimum alternative (Iyengar et al., 2006). Maximization is defined as the "decision-making style that involves seeking the single best option when making a choice" (Dahling \& Thompson, 2012). Maximization is employed in career choices because individuals often have to choose from a wide array of vocations, occupations and jobs; after taking into consideration a variety of aspects, including matching of talents and 
competencies, salary, the organizational background, advancement opportunities, and so on. A maximizer is a person who has a desire to make optimal decisions (Sulphey, 2014; Voss et al., 2018). Many social scientists have conceptualized maximizing as an individual trait (Diab, et al., 2008; Schwartz et al., 2002). Though many definitions about maximization exist, only few have defined career maximization. Voss et al. (2019) draw extensively from literature related to maximization and career decisions defined career maximizing as "the extent to which a person desires to make career decisions in pursuit of maximizing goals". According to them career maximizing is a continuous variable that exists as a matter of degree rather than being categorical. Though a few studies have been undertaken about maximization in general and career maximization in particular, its relationship with organizational behavior concepts are scarce. The present study is undertaken to fill this gap in literature. The objective of the present study is to find out the relationship between career maximization and employee engagement.

\section{Review of Literature}

A career is considered to be the process wherein individuals narrow down their life choices, wherein they create and find themselves (Gottfredson, 2002). A few theories have portrayed the principles that individuals use to choose their career. Some theories state that that individuals often search for the appropriate environments that could match their unique abilities, attitudes, and values. This aspect was presented by renowned person-environment career theory approach. Classical examples are Theory of Vocational Personalities of Holland (1985) and Theory of Career Anchors by Schein (1996). These two theories propose that throughout their career, individuals will ultimately discover and accomplish the vocation that best fits their personality profile. Career choice and development approach of Super (1990) is another influential theory in career and organizational practice literature. This theory describes the various stages through which the various career paths develop.

Research about the aspect of maximization has its moorings in Simon's (1955) theory based on the model of rational choice. The theory proposed that individuals take "calculated decisions" which are based on a complete understanding of the available options that strives to maximize personal utility. Thus, while maximizing, individuals evaluate exhaustively all the available choices and choose the option which bests suits him/her. However, true maximization in decision making is not possible, and decisions are normally taken under certain conditions of "bounded rationality" wherein only limited information are available. Further, any individual does have a form of inherent limited decision-making abilities (Simon, 1955, 1957).

Maximizing decisions would bring in happier and better outcomes, since such decisions are taken after cautious evaluation of all available options. However, in reality maximized decisions have been found to be normally dysfunctional since humans have limited abilities to evaluate all available options in a rational manner and identify the best choice (Dahling \& Thompson, 2012; Reardon \& Miller, 2012). They are prone to miss optimal choices, and could experience a sense of regret despite careful evaluation of the situation. This is in line with the proposition of Simon (1955) that human, which making a decision, possess only "bounded rationality" and often lack the mental and physical ability to judiciously evaluate all possible options. This has been proven empirically by a number of studies.

Though maximized decisions are taken after considerable caution and evaluation, in anticipation of happier and better outcomes, empirical evidences suggest a paradoxically opposite result. However, after taking the decision, those who have involved in maximized decisions become less satisfied than those who were low in maximization (Dar-Nimrod et al., 2009; Iyengar et al., 2006; Larsen \& McKibban, 2008; Parker, et al., 2007; Voss et al., 2019).

Iyengar et al. (2006) observed maximizers to secure jobs with higher initial salary. However, their satisfaction levels were lesser during and after the job search. Research also showed that individuals attempting to maximize their decisions, when provided with multiple decision choices are most likely to experience negative emotions (Schwartz et al., 2002). They found that experience reduced general well-being (Schwartz, 2000). This was observed to be severe in situations where multiple decision options were available (Iyengar \& Lepper, 2000). Taking decisions with respect to career is one such instance (Dahling \& Thompson, 2012). This is because it is impossible to identify the best and most optimal career (van Vianen et al., 2009). It is here that the servicers of career counsellors could be availed. They could provide people with the required career information and facilitate their clients to take appropriate career decisions and a separate identity, so that they need not be regretted on a later time (Sulphey, 2019). Alternatively, they could also facilitate career adaptability that could reduce the impact of career regret (van Vianen, 2009).

The other construct that is studied is employee engagement (EE). The construct of EE, which is of recent origin, is "the measurable degree of an employee's positive or negative emotional attachment to their job, colleagues and organisation that profoundly influences their willingness to learn and perform at work" (Sandhya \& Sulphey, 2019). It is also defined as a "positive, fulfilling work-related state of mind that is characterized by vigor, dedication and absorption" (Schaufeli, 2002). $\mathrm{EE}$ is an affective cognitive state which is considered to be more persistent and pervasive in nature. It is not momentary, and is generally not limited to any specific individual, object, event or behavior (Sandhya \& Sulphey, 2019). In general it can be considered as a state of mind that is capable of bringing in involvement, commitment and satisfaction in the workplace. Scarlett (2010) states that it is capable of bringing in positive or negative emotional attachment to the job. It could also influence the willingness of individuals to learn and perform better. The construct of EE is widely researched and has been 
found to be capable of eliciting positive responses at the workplace. It has been found to enhance employee empowerment, psychological contact and reduce turnover intentions (Sandhya \& Sulphey, (in print).

\section{Methodology}

\subsection{Data collection}

Two standardized questionnaires were used to collect the required data for the study. The details of which are as under:

1. Career maximization was measured using a 10 items Career Maximation Scale (CMS) developed by Voss et al. (2019). It is a unidimensional scale that has favorable psychometric properties. With an alpha of .88 the scale enjoys good internal consistency and adequate fits. The scale of CMS is on five-points ranging from strongly agree to strongly disagree. Sample items include "I choose jobs that will maximize my career, and When choosing a career" and "I always try to choose the best one".

2. Employee Engagement was measured using the UWES-3 (Schaufeli, 2017). The tool that measures employee engagement has been validated in five different culture and is widely used. It has high internal consistency and factorial validity, and is hence a reliable and valid tool to measure work engagement. It has three dimensions of vigor, dedication and absorption. Sample item include "I am enthusiastic about my job". The UWES-3 is on a five five-points ranging from strongly agree to strongly disagree.

Data for the study was collected from a sample of 308 gainfully employed respondents. Data was collected online from members of a few social media groups. The respondents were assured confidentiality and assured that the responses would be used for research purposes only. Since the data was collected online using Google docs, no data was missing and all the responses could be used for the study. The demographics of the respondents like age, gender, years of experience, nationality, etc. were also collected. The respondents belonged to diverse demographics, the details of which are presented in Fig. 1.

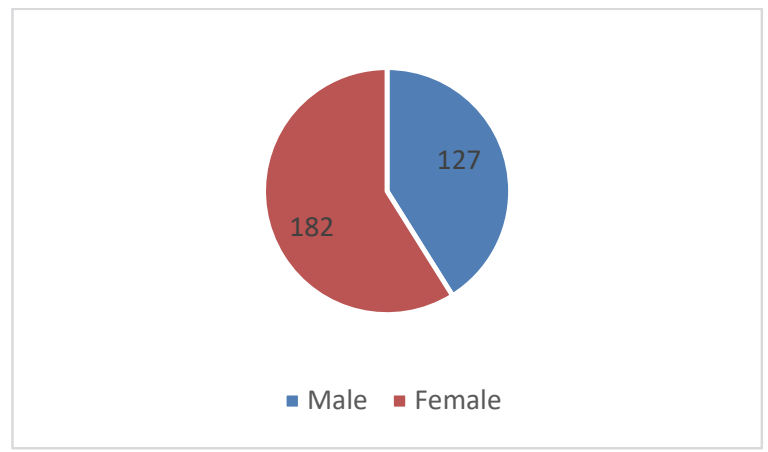

Gender

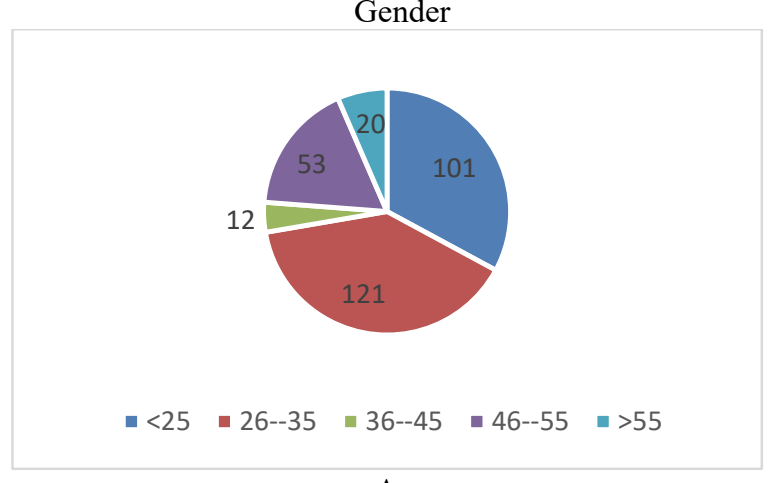

Age

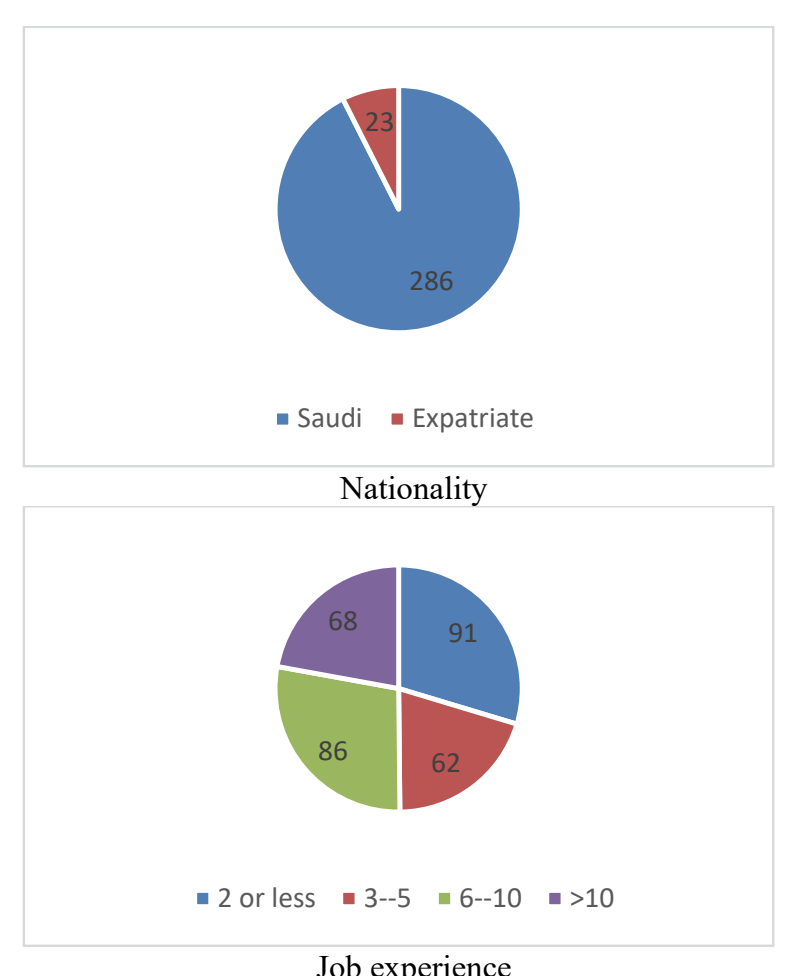

Job experience

Fig. 1. Personal characteristics of the participants

The minimum age of the respondents was 18 and the maximum 54 years. The average age of the sample is 31 years. The experience of the respondents varied from less than a year to over 30 years. The average experience of the sample in their professions was fond to be 7.2 years. It can be observed from Fig. 1 that the respondents belonged to a wide diversity of demographics, and hence the sample can be considered representative in nature.

\section{Results and discussion}

The collected data was analyzed using statistical tools like t-test, ANOVA, correlation, regression, etc. The details of the analysis are presented in the following sections. The descriptive statistics is presented in Table 1. 
The reliability of the questionnaires was also assessed using Cronbach Alpha. The alpha value was .806 for career maximization and .798 for employee engagement. This indicates the reliability of the tools used for collection of data. This is well within the rule of thumb prescribed by Nunnally and Bernstein (1994).

Table 1

Descriptive statistics

\begin{tabular}{lcc}
\multicolumn{1}{c}{ Details } & Career maximization & Employee engagement \\
\hline Minimum score & 15 & 3 \\
Maximum score & 50 & 15 \\
Mean score & 40.81 & 11.87 \\
Standard deviation & 5.50 & 2.36 \\
Cronbach Alpha & .806 & .798 \\
\hline
\end{tabular}

Note : $\quad \mathrm{N}=307$

Source : Authors' calculation

The correlation analysis was done to find out if there exists any relationship between the variables under study. The results of the correlation analyses are presented in Table 2 . It can be seen from the table that significant correlation at 0.01 level was observed between Career maximization and employee engagement $(\mathrm{r}=.291)$. This finding is a new addition to management literature as no previous studies has been undertaken to identify this relationship.

No significant relation was however found between career maximization or employee engagement, and age as well as experience. This denotes that these age and experience does not in any way exercise any relationship with the two variables studied. Both career maximization and employee engagement were found to be independent of demographics studied.

Table 2

Correlation matrix

\begin{tabular}{lcccc} 
& Career maximization & Employee engagement & Age & Experience \\
\hline Career maximization & 1 & $.291^{*}$ & .004 & .046 \\
Employee engagement & & 1 & .040 & .037 \\
Age & & 1 & $.818^{*}$ \\
Experience & & & 1 \\
\hline Note $:$ & $* *$ Correlation is significant at the 0.01 level & \\
Source $::$ & $\quad$ Authors' calculation & & \\
\hline
\end{tabular}

Regression analysis was done to find out the impact of career maximization on employee engagement. As indicated by the results the $\mathrm{R}^{2}$ was .085 which denotes that a very high percent of variation in employee engagement is explained by career maximization. ANOVA was applied to test the significance, and the F statistic value was 28.264. This value is found to be significant. This denotes that the regression model is adequate, indicating that career maximization has a significant contribution towards employee engagement.

Table 3

Result of Regression analysis

\begin{tabular}{lcccc}
\hline \multicolumn{1}{c}{ Model } & $\mathrm{B}$ & Std. error & $\mathrm{T}$ & Significance \\
\hline Constant & 6.772 & .967 & 7.004 & .000 \\
Career maximization & .125 & .023 & 5.316 & .000 \\
\hline Dependent variable: $\quad$ Employee engagement & $\mathrm{R}^{2}=.085$ & & &
\end{tabular}

The sample collected for the study was classified as high medium based on career maximization. While those having scores over Mean plus half of standard deviation (43.57) was considered as high group, those below mean minus half standard deviation (38.06) was considered as low group. Those having scores between the two were classified as middle group. Based on this, it was found that 100 samples were having scores over 43.57, and hence classified as high group. 83 samples were having scores below 38.06 and hence were classified as low group. Thus 124 samples pertained to the middle group. To further examine the impact of high or low scores of career maximization on employee engagement, correlation analysis between the two variables were done for the high group of samples. The $\mathrm{r}$ value was found to be .237 , which is significant at .05 level $(\mathrm{N}=100)$. Correlation analysis was then conducted on the low group and the $\mathrm{r}$ value was found to be .263 , which is also significant at .05 level $(\mathrm{N}=83)$. The finding is of significance, as it shows that both the groups - high and low did not have any differences with respect to the level of employee engagement. In this regard it needs to be noted that the $r$ value for the overall samples was .291, which was significant at .01 level. It can thus be considered that though career maximization influences employee engagement, high or low levels of the variable did not have a significant impact on the dependent variable. This finding is a new addition to management literature, and can be considered as an aspect which needs to be probed further. An attempt was also made to find out the if there was any difference between male and female respondents with respect to the variable studied. $\mathrm{t}$ - test was done towards this, and the results are presented in Table 4. 
Table 4

Data and value for t-test

\begin{tabular}{cllllll}
\hline Variable & Gender & $\mathrm{N}$ & Mean & S.D. & S.E. Mean & t-value \\
\hline Career maximization & Male & 126 & 41.39 & 5.049 & .450 & \multirow{2}{*}{$1.569 \mathrm{NS}$} \\
& Female & 181 & 40.41 & 5.766 & .429 & \\
\hline Employee engagement & Male & 126 & 12.13 & 2.091 & .186 & \multirow{2}{*}{$1.727 \mathrm{NS}$} \\
& Female & 181 & 11.68 & 2.512 & .187 & \\
\hline
\end{tabular}

Note: NS - not significant

The t-values of the two variables with respect to gender were found to be not significant, signifying that there is no significant difference between them. However, the mean value for males for both the variables (Career maximization - 41.39 and Employee engagement - 12.13) were found to be higher. This indicates that males are having better career maximization and employee engagement than females.

\section{Discussion and conclusion}

Research about career maximization is still evolving. Maximisers have been found to be less constructive in their decisionmaking styles (Schwartz et al., 2002) as they set unattainable goals (Parker, et al., 2007). Earlier studies (for example DarNimrod, et al., 2009; Larsen \& McKibban, 2008; Parker, et al., 2007) found that people having high scores in maximization are less satisfied with their decisions. The present study was undertaken with the primary objective of understating the relationship between career maximization and employee engagement. Since maximized decisions are taken after due consideration, cautious evaluation and prudent decision making, it is expected to bring in better outcomes. Based on this it was considered that those having higher levels of career maximization would have better employee engagement. The present study found that career maximization was a significant predictor of employee engagement, the levels of maximization had no impact on the dependent variable. This is evident from the more or less similar levels of significance in correlations, for both the samples having high and low scores of career maximization. The finding is a fresh addition to management literature, as no studies have been undertaken earlier to explore this relationship. The result needs to be analyzed with the earlier finding of Parker et al. (2007) that maximisers reported certain maladaptive styles of decision-making. They also tend to have lesser coping behaviors, over dependencies, decision avoidance (due to taking more time for examining options in detail) as well as higher levels of decision regret. van Vianen et. al. (2009) suggest that rationality and intuition could help in tiding over the problems associated with career maximization. Since career and vocation decisions are usually made under conditions of extreme uncertainty, it would be ideal in basing it on prudence rationality and intuition. Further, corporate mentoring has also been found to aid positive attitude at workplace (Sulphey, 2017). Earlier career literature provided evidences to support the view that if individuals have the opportunity to choose their career, they would be better satisfied and engaged (Brown \& Associates, 2002). However, recent evidences prove the opposite. Vianen et al. (2009) opined that when individuals are in a situation, wherein they are more choices, they are often less happy. The also face the situation of the so called "tyranny of freedom" (Schwartz, 2000). All these calls for more in-depth and intensive studies in this area.

As in most other studies, correlations were used to arrive at the results. There could be other factors and variables that could encourage maximization, which were not considered in the present study. For instance, higher risk levels and lesser resources availability could influence decision making process. There could be other complex associations that could cause or mediate the relationship between the variables, which were not examined in the present study. There is a scope for the conduct of experimental studies, through control of variables that might offer further evidences about the causal relationships. There is, as such, ample opportunity for the conduct for further studies in this area. It is expected that more studies are undertaken in this fecund area.

\section{References}

Brown, D., \& Associates (Eds.). (2002). Career choice and development (4th ed.). San Francisco: Jossey-Bass.

Dahling, J. J. \& Thompson, M. N. (2012). Detrimental relations of maximization with academic and career attitudes. Journal of Career Assessment, 21(2) 278-294.

Dar-Nimrod, I., Rawn, C. D., Lehman, D. R., \& Schwartz, B. (2009). The maximization paradox: The costs of seeking alternatives. Personality and Individual Differences, 46, 631-635.

Diab, D. L., Gillespie, M. A., \& Highhouse, S. (2008). Are maximizers really unhappy? The measurement of maximizing tendency. Judgment and Decision Making, 3, 364-370.

Goffman, E. (1968). Asylums. Harmondsworth: Penguin.

Gottfredson, L. S. (2002). Gottfredson's theory of circumscription, compromise, and self-creation. In D. Brown \& Associates (Eds.), Career choice and development (4th ed., pp. 85-148). San Francisco: Jossey-Bass.

Holland, J. L. (1985). Making vocational choices: A theory of vocational personalities and work environments. Englewood Cliffs, NJ: Prentice Hal.

Hughes, E. (1937). Institutional Office and the Person. American Journal of Sociology, 43, 404-13. 
Iyengar, S. S., Wells, R. E., \& Schwartz, B. (2006). Doing better but feeling worse: Looking for the "best"' job undermines satisfaction. Psychological Science, 17, 143-150.

Larsen, J. T., \& McKibban, A. R. (2008). Is happiness having what you want, wanting what you have, or both? Psychological Science, 19, 371-377.

Nunnally, J. C. \& Bernstein, I. H. (1994). Psychometric Theory. (3rd ed.). New York: McGraw-Hill.

Parker, A. M., de Bruin, W. B. \& Fischhoff, B (2007). Maximizers versus satisficers: Decision-making styles, competence, and outcomes, Judgment and Decision Making, 2(6), 342-350.

Reardon, J \& Miller, C. (2012). The effect of response scale type on cross-cultural construct measures: An empirical example using Hall's concept of context, International Marketing Review, 29(1), 24-53.

Sandhya, S. \& Sulphey, M.M. (2019). An assessment of contribution of employee engagement, psychological contract and psychological empowerment towards turnover intentions of IT employees', International Journal of Environment, Workplace and Employment, 5(1), 22-31.

Sandhya, S. \& Sulphey, M. M. (in print). Influence of Empowerment, Psychological Contract and Employee engagement on Voluntary Turnover Intentions, International Journal of Productivity and Performance Management.

Scarlett, K. (2010). Quality Employee Engagement Measurement, in The New HR Analytics Jac Fitz-enz, pp 108-122.

Schaufeli, W. B., Shimazu, A., Hakanen, J., Salanova, M., \& De Witte, H. (2019). An ultra-short measure for work engagement: The UWES-3 validation across five countries. European Journal of Psychological Assessment, 35(4), 577.

Schein, E. H. (1996). Career anchors revisited: Implications for career development in the 21 st century. Academy of Management Executive, 10, 80-88.

Schwartz, B. Ward, A., Monterosso, J. Lyubomirsky, S., White, K., \& Lehman, D. R. (2002). Maximizing versus satisficing: Happiness is a matter of choice. Journal of Personality and Social Psychology, 83, 1178-1197.

Simon, H. A. (1955). A behavioral model of rational choice. The Quarterly Journal of Economics, 69, 99-118.

Simon, H. A. (1957). Models of man, social and rational: Mathematical essays on rational human behavior. New York, NY: John Wiley.

Simon, H. A. (1978). Rationality and process and product of thought. American Economic Review, 68, 1-16.

Sulphey, M. M. (2014). Behavioural Finance, New Delhi: PHI Learning Pvt. Ltd.

Sulphey, M. M. (2017). The Prospects of Corporate Mentoring in Enhancing Employability of Business Graduates in Saudi Arabia, International Business Management, 11(4), 895-903.

Sulphey, M. M. (2019). The Concept of Workplace Identity, its evolution, antecedents and development, Journal of Environment, Workplace and Employment, 5(2), 151 - 168.

Super, D. E. (1990). A life-span, life-space approach to career development. In D. Brown, L. Brooks, \& Associates (Eds.), Career choice and development \{2nd ed., pp. 197-261). San Francisco: Jossey-Bass.

van Vianen, A. E. M., De Pater, I. E., \& Preenen, P. T. Y. (2009). Acceptable careers: Maximizing less and exploring more. The Career Development Quarterly, 57, 298-309.

Voss, N. N., Lake, C. J. \& Chlevin-Thiele, C. (2019). Construction and initial validation of the career maximizing scale. Career Development Quarterly, 67, 157-179.

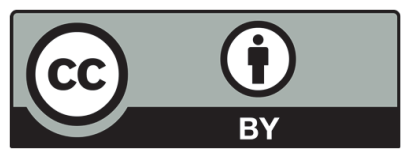

(C) 2020 by the authors; licensee Growing Science, Canada. This is an open access article distributed under the terms and conditions of the Creative Commons Attribution (CC-BY) license (http://creativecommons.org/licenses/by/4.0/). 